\title{
Intra-individual associations between intentional self-regulation and prosocial behavior during adolescence: Evidence for bidirectionality
}

\author{
Laura M. Padilla-Walker \\ Brigham Young University, laura_walker@byu.edu \\ Madison Memmott-Elison \\ Jeremy B. Yorgason \\ Sarah M. Coyne
}

Follow this and additional works at: https://scholarsarchive.byu.edu/facpub

Part of the Social and Behavioral Sciences Commons

\section{Original Publication Citation}

Memmott-Elison, M. K., Padilla-Walker, L. M., Yorgason, J., \& Coyne, S. M. (2020). Intra-individual associations between intentional self-regulation and prosocial behavior during adolescence:

Evidence for bidirectionality. Journal of Adolescence, 80, 29-40.

\section{BYU ScholarsArchive Citation}

Padilla-Walker, Laura M.; Memmott-Elison, Madison; Yorgason, Jeremy B.; and Coyne, Sarah M., "Intraindividual associations between intentional self-regulation and prosocial behavior during adolescence: Evidence for bidirectionality" (2020). Faculty Publications. 5504.

https://scholarsarchive.byu.edu/facpub/5504

This Peer-Reviewed Article is brought to you for free and open access by BYU ScholarsArchive. It has been accepted for inclusion in Faculty Publications by an authorized administrator of BYU ScholarsArchive. For more information, please contact ellen_amatangelo@byu.edu. 


\title{
Intra-individual associations between intentional self-regulation and prosocial behavior during adolescence: Evidence for bidirectionality
}

\author{
Madison Memmott-Elison ${ }^{\mathrm{a}, *}$, Laura M. Padilla-Walker ${ }^{\mathrm{b}}$, Jeremy B. Yorgason ${ }^{\mathrm{b}}$, \\ Sarah M. Coyne ${ }^{\mathrm{b}}$
}

${ }^{\mathrm{a}}$ University of Missouri, USA

${ }^{\mathrm{b}}$ Brigham Young University, USA

\section{A R T I C L E I N F O}

\section{Keywords:}

Prosocial behavior

Intentional self-regulation

Bidirectionality

Adolescence

\begin{abstract}
A B S T R A C T
Introduction: Couched in Positive Youth Development (PYD) theory and relevant empirical work, this study investigated bidirectional associations between intentional self-regulation and prosocial behavior toward strangers from age 12 to age 18 .

Method: Participants included 500 adolescents (52\% female, 77\% European American; age Time $1=12$ years, Time $2=14$ years, Time $3=16$ years, Time $4=18$ years) from the Northwestern United States. Adolescents self-reported on their intentional self-regulation and prosocial behavior toward strangers across four time points. A random-intercept cross-lagged panel model (RICLPM) was estimated in order to assess bidirectionality while avoiding conflating intra- and inter-individual variability.

Results: Results revealed intentional self-regulation and prosocial behavior toward strangers were bidirectionally related during early adolescence (i.e., from age 12 to 14). During mid-to-late adolescence (i.e. age 14 to 18), prosocial behavior toward strangers facilitated intentional selfregulation, whereas intentional self-regulation did not drive the development of prosocial behavior toward strangers.

Conclusions: Findings indicate that early adolescence may be a particularly plastic developmental period in terms of PYD. Findings also suggest that investigations of relations between adolescents' personal assets and contribution factors merit further scholarly attention. Several directions for future research are presented.
\end{abstract}

\section{Introduction}

Lerner, Lerner, Bowers, and Geldhof's (2015) Positive Youth Development (PYD) perspective denotes intentional self-regulation as a powerful personal asset utilized by adolescents to engage in myriad positive behaviors over time, including prosocial behavior. This PYD perspective and analogous research suggest that prosocial behavior might also promote or activate positive outcomes such as enhanced self-regulatory skills (Eisenberg et al., 1996; Lerner, Lerner, Bowers, \& Geldhof, 2015), though empirical support in this area is in need of strengthening. During adolescence, intentional self-regulatory abilities are continually fine-tuned (Gestsdottir \& Lerner, 2008), and opportunities for prosocial behavior expand (Padilla-Walker, Dyer, Yorgason, Fraser, \& Coyne, 2015a) in response

\footnotetext{
${ }^{*}$ Corresponding author. 314 Gentry Hall, Columbia, MO, 65201, USA.

E-mail addresses: madimemmott@gmail.com, mkegn2@mail.missouri.edu (M. Memmott-Elison).
} 
to novel cognitive, social, and emotional demands that characterize this period (e.g., Arnett, 2000; Gilchrist, 2017; Steinberg, 2005). Therefore, adolescents are at a developmental, transitional crossroad that is characterized by the potential for positive development, though the majority of past research focuses solely on negative adolescent adjustment (e.g., Ary et al., 1999; Card \& Little, 2006). Thus, understanding how two positive features of development-that both are couched within a PYD perspective-might influence the other over time has significant implications for future basic and applied research. For instance, findings will address previously overlooked theoretical bidirectional relations between PYD features, thereby potentially supporting claims that PYD is nonrecursive in nature due to individuals acting as producers of their own development (Lerner \& Busch-Rossnagel, 1981; Lerner \& Walls, 1999). Additionally, findings might focus intervention efforts aimed toward developing individuals' self-regulatory skills, including selfregulated learning education programs (Boekaerts \& Corno, 2005), therapeutic approaches (e.g., Attention Bias Modification, Cognitive Behavior Therapy, Mental Contrasting with Implementation Intentions), mindfulness training, and employment training, amongst others (Cavadel, Kauff, Anderson, McConnell, \& Derr, 2016). Therefore, with the prospective of validating the bidirectional tenet of the PYD perspective, building upon limited empirical work, and informing preemptive intervention programs, the current study aimed to assess longitudinal, bidirectional relations between intentional self-regulation and prosocial behavior toward strangers from early to late adolescence (i.e., 12-18 years).

\subsection{The positive youth development perspective}

Lerner and colleagues' (2015) PYD perspective is based on previous PYD theories as well as recent reworkings of Relational Developmental Systems Theory (the R-DST, Overton, 2013; Overton \& Lerner, 2012). This perspective asserts bidirectional person $\leftarrow$ $\rightarrow$ context exchanges, referred to as developmental regulations, are created by coactions between adolescents' ecological and personal assets. Adaptive developmental regulations, which are central to Lerner and colleagues' (2015) PYD perspective, occur when person $\leftarrow \rightarrow$ context exchanges are mutually beneficial, and are facilitative of features of PYD (i.e., caring, character, competence, confidence, connection). In turn, PYD outcomes promote adolescent contribution (i.e., to self, family, community, and civil society) and personal adjustment (i.e., decreased depression, delinquency, substance use, etc.) (Bowers, Gestsdottir, Geldhof, Nikitin, \& von Eye, 2011; Lerner Brentano, Dowling, \& Anderson, 2002; Lerner et al., 2015). Lerner and colleagues' (2015) PYD perspective also includes the explicit assertion that adolescents' contribution and adjustment inform personal and ecological assets over time. However, investigations of these theoretical tenets have remained largely unexplored in past basic research efforts (for an exception, see Schmid, Phelps, \& Lerner, 2011), partly due to the challenging landscape relevant to measuring plastic PYD constructs over time (Lerner et al., 2015). This plasticity is based in large part on the underlying assumption that individuals play an active role in their own positive development across time (Lerner \& Busch-Rossnagel, 1981; Lerner \& Walls, 1999). Taken together, Lerner and colleagues' (2015) PYD perspective emphasizes integration across levels of individuals' ecologies. See Fig. 1 for an adapted visual representation of Lerner and colleagues' (2015) PYD perspective.

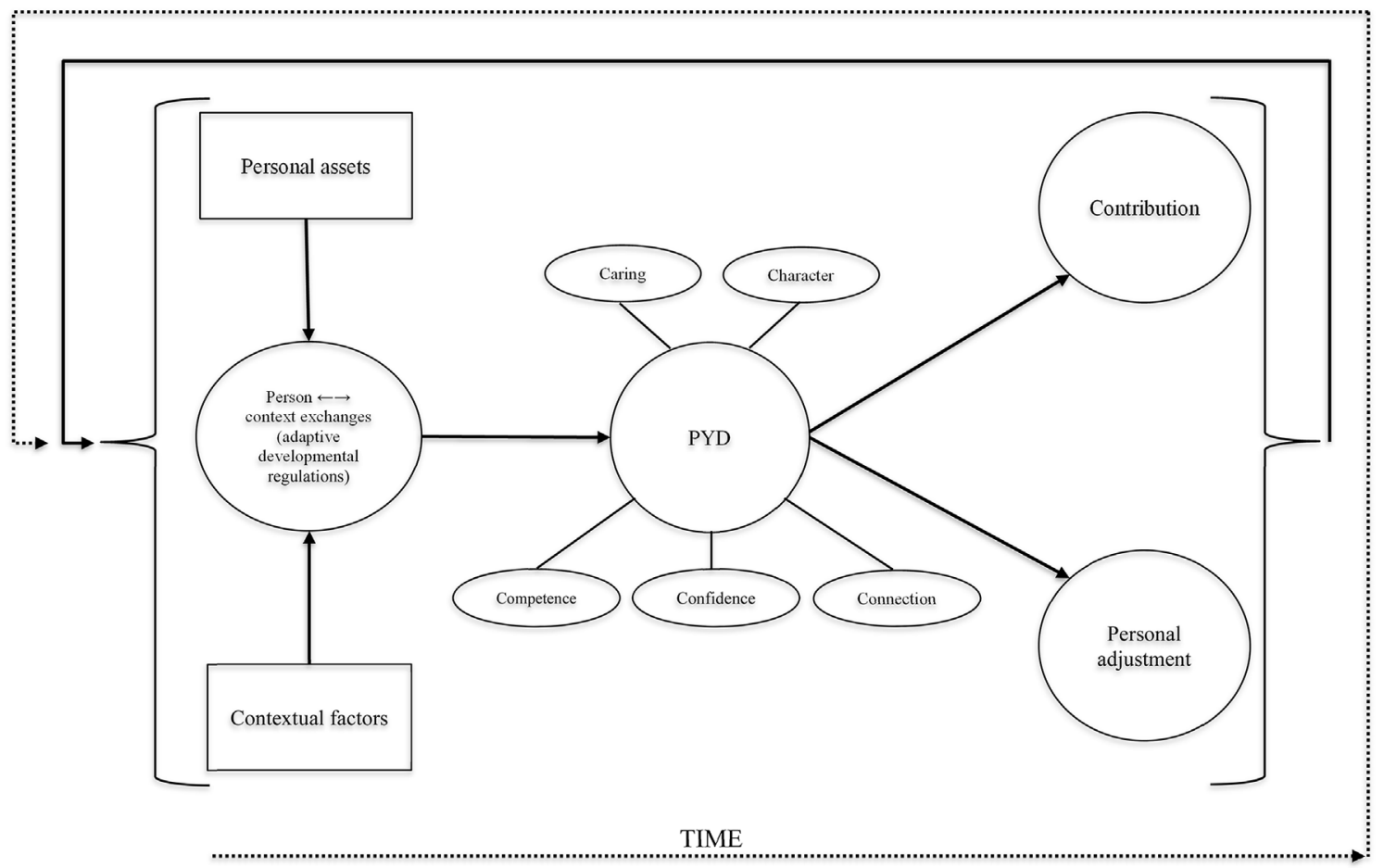

Fig. 1. An adapted visual representation of the PYD perspective taken from Lerner et al., 2015. 


\subsection{Relations between intentional self-regulation and prosocial behavior toward strangers}

Intentional self-regulation and prosocial behavior are two constructs that have been repeatedly individually investigated from the PYD perspective. Intentional self-regulation includes the power to control one's consciousness (including thoughts) and behaviors in a goal-oriented fashion (Binswanger, 1991; Bowers et al., 2011). Prosocial behavior toward strangers is best defined as voluntary behavior intended to benefit those with whom an individual does not have an established relationship (e.g., strangers, Eisenberg, Spinrad, \& Knafo-Noam, 2015). Given adolescents report engaging in varying amounts of prosocial behavior toward strangers (Padilla-Walker et al., 2015a), and their intentional self-regulatory capacities are continually fine-tuned across the adolescent period (Bowers et al., 2011), it is especially important to understand how these constructs influence the other over time, through a direct test of Lerner and colleagues' (2015) PYD perspective.

\subsubsection{Intentional self-regulation promotes prosocial behavior}

Lerner and colleagues' (2015) PYD perspective consistently frames intentional self-regulation as a personal asset (e.g., Gestsdottir \& Lerner, 2008). Therefore, intentional self-regulation facilitates positive adolescent outcomes (i.e., PYD features, contribution, and positive adjustment), including prosocial behavior toward strangers (Lerner, Brentano, Dowling, \& Anderson, 2002; Lewin-Bizan, Bowers, \& Lerner, 2010). This is especially likely when adolescents have had prior access to valuable ecological assets (e.g., prosocial models, participation in volunteer programs, etc.). Adolescents who are intentionally well-regulated must transcend nervousness or other possible negative affect, focus their attention on the present helping situation, decide on the most appropriate way to help a person they do not know, and be motivated to act in accordance with their decision to help another-all while maintaining their personal goal(s) or plan(s). In the context of these adaptive developmental regulations, it is probable that adolescents are inclined to help needy strangers when their intentional self-regulation acts as motivation to do so (Bandura, 1991; Bandura \& Simon, 1977). For instance, adolescents may use their intentional self-regulation to actively create, maintain, and achieve prosocial goals (Hardy \& Carlo, 2005; Hart, Atkins, \& Ford, 1998). The PYD perspective's proposed link between intentional self-regulation and prosocial behavior toward strangers is additionally supported by a growing literature (e.g., DeWall, Baumeister, Gailliot, \& Maner, 2008; Flook, Goldberg, Pinger, \& Davidson, 2015; Martinsson, Myrseth, \& Wollbrant, 2010; Mead, Baumeister, Gino, Schweitzer, \& Ariely, 2009; Padilla-Walker \& Christensen, 2011). Thus, it is reasonable to expect intentional self-regulation longitudinally drives the development of prosocial behavior toward strangers (Lewin-Bizan et al., 2010).

Intentional self-regulation and prosocial behavior toward strangers may be especially strongly associated during early adolescence. For instance, early adolescence is a period when intentional self-regulatory processes have been recently cued in relation to developmentally salient changes and transitions (Steinberg, 2005; 2010), whereas the novelty of intentional self-regulation implementation is less relevant during middle-to-late adolescence. Further, prosocial behavior toward strangers tends to increase from early to middle adolescence (Padilla-Walker, Carlo, \& Memmott-Elison, 2018), perhaps because young adolescents have more opportunities than ever before to interact with (e.g., behave prosocially toward) strangers as they transition from Elementary school to Middle school. During this transition, young adolescents' educational environments are inundated with primarily unknown peers (Hardy, Bukowski, \& Sippola, 2002). Additionally, by mid-adolescence, youth are adept at implementing prosocial strategies in order to build friendships or earn social capital and power (Li \& Wright, 2014). Therefore, due to the simultaneous stimulation of intentional self-regulation and expanded opportunities for prosocial behavior toward strangers, as well as the adaptable role of prosocial behavior toward strangers during early adolescence, intentional self-regulation and prosocial behavior toward strangers may be more consistently reciprocally related during early adolescence than during middle-to-late adolescence.

\subsubsection{Prosocial behavior drives intentional self-regulation}

Lerner and colleagues' (2015) PYD perspective most consistently operationalizes prosocial behavior toward strangers as a form of adolescent contribution to community (Geldhof et al., 2014). Furthermore, Lerner and colleagues' (2015) PYD perspective also conceptually implicates prosocial behavior as a person $\leftarrow \rightarrow$ context exchange in itself because engaging in prosocial behavior involves personal dispositions or willingness to help others (i.e. a personal asset) along with ecological factors (e.g., social context, emotional or physical access to resources, etc.) (Lerner et al., 2002). Conversely, meta-PYD theories suggest prosocial behavior is a feature of PYD in itself (Damon, 2004; Larson, 2000). Such varying conceptualizations and according operationalizations of prosocial behavior within the broad PYD literature can make empirical tests of the framework ambiguous, particularly when focused on adolescents' prosociality.

Despite these inconsistencies, or perhaps in light of them, there are compelling postulatory reasons to expect prosocial behavior drives the development of intentional self-regulation during adolescence, at least in some part. For example, whether prosocial behavior toward strangers is framed as a contributory behavior, as a person $\leftarrow \rightarrow$ context exchange in itself, or even as an indicator of PYD, Lerner and colleagues' (2015) PYD perspective asserts it should inform any further development of personal assets (e.g., intentional self-regulation) and adaptive developmental regulations as time progresses. This is because of integration that occurs across individuals' personal characteristics and ecologies. In other words, as individuals engage in prosocial behavior toward strangers, their capacities and/or employment of personal assets, including intentional self-regulation, will be strengthened as a function of the integrated PYD process. This concept is similar to that of "positive cascades" presented by Masten and Cicchetti (2010), in which positive function in one domain or system cascades (or overflows) into other positive domains and systems, altering the functioning thereof. A positive cascade may be initiated when adolescents engage in a given behavior (e.g., prosocial behavior toward strangers) and will continue to flow across individuals' personal assets and ecologies, including intentional self-regulation (Lerner et al., 2002; 2005). 
In addition to this broad explanation, there are also specific justifications for why prosocial behavior toward strangers likely facilitates the development of intentional self-regulation. First, helping a stranger can be considered high-cost (Padilla-Walker \& Carlo, 2014), since there is typically no relational foundation for helping, and therefore the course of helpful action and how the target may respond to being helped is likely unknown to the actor. Moreover, helping a stranger requires adolescents to (a) be aware of and recognize opportunities to help a person they do not know, (b) evaluate whether their helpful act would be well-received, (c) weigh the potential risks and benefits of helping that stranger, and (d) choose the most effective course of helpful action. Each of these steps utilize adolescents' intentional self-regulation to some degree. Therefore, helping strangers may exercise individuals' intentional self-regulation, and therefore facilitate its development though use (Muraven \& Baumeister, 2000; Muraven, Baumeister, \& Tice, 1999). Second, it is likely that after engaging in prosocial behavior toward strangers once or a few times, youth may seek additional opportunities to help strangers perhaps in order to gain social capital (Li \& Wright, 2014), or feel as though they are behaving according to their developing moral identity (Winterich, Aquino, Mittal, \& Swartz, 2013). As youth become proficient at engaging in prosocial behavior toward strangers, and become familiar with the according intangible assets, they may develop the goal to help strangers more often. Thus, engagement in prosocial behavior toward strangers may enthuse intentional self-regulation development. Limited interdisciplinary research provides additional empirical support for the role of prosocial behavior in driving self-regulatory development (e.g., see Conway \& Peetz, 2012; Eisenberg et al., 1996; Normandeau \& Guay, 1998; Sachdeva, Iliev, \& Medin, 2009).

It is important to note that there is far less research that suggests prosocial behavior drives intentional self-regulation than the opposite, though this work is promising. Also, we are unaware of any extant research that asserts the existence of bidirectional associations between prosocial behavior toward strangers and intentional self-regulation, or that tests this portion of the PYD perspective. The findings of this study therefore have the potential to inform future empirical work and further explain and strengthen Lerner and colleagues' (2015) PYD perspective. Additional longitudinal evidence for and critiquing of Lerner and colleagues' (2015) PYD perspective is warranted, given a sizable number of current PYD studies have been conducted using the same (4-H study) dataset (e.g., Bowers et al., 2011; Jelicic, Bobek, Phelps, Lerner, \& Lerner, 2007; Lerner et al., 2017, 2005; Phelps et al., 2009).

\subsection{Dimensional specificity in operationalizations of self-regulation and prosocial behavior}

For the past several decades, scholars have warned against the growing definitional chaos that denotes the self-regulation literature (McClelland, Ponitz, Messersmith, \& Tominey, 2010). Recently, Nigg (2017) asserted that the remedy is to clearly and correctly conceptualize and operationalize various dimensions of self-regulation across basic and applied work. Analogous to this call for operational specificity in the dimensionality of self-regulation, we chose to explicitly and solely focus on intentional self-regulation in the current study, which corresponds to notions of top-down self-regulation and long-term self-regulation in the broader research literature. We chose to explore the role of intentional self-regulation in the current study because of its integral role in PYD processes and outcomes (Bowers et al., 2011; Lerner et al., 2015), and because of promising research that suggests it may be uniquely related to prosocial behavior toward strangers (DeWall et al., 2008).

Additionally, recent research extends beyond the conventional study of prosocial behavior toward unidentified others and calls for a target-specific approach (Padilla-Walker \& Carlo, 2014), which includes studying prosocial behavior in relation to the person who is being helped. The current study focuses on strangers as recipients, or targets, of adolescents' prosocial behavior. Research has progressed to taking a target-specific approach because past work suggests that prosocial behavior is differentially related to adjustment outcomes, and follows varying developmental patterns, depending on whom a helper chooses to assist (see Güroğlu, van den Bos, \& Crone, 2014; Padilla-Walker et al., 2015a; Padilla-Walker, Carlo, \& Nielson, 2015b). For instance, engagement in prosocial behavior toward strangers is considered a special marker of morality, since personal characteristics such as self-regulation and sympathy (Padilla-Walker \& Christensen, 2011) likely motivate helping strangers, as opposed to a preexisting relationship in need of reparation or strengthening (as is the case with prosocial behavior toward friends or family; Hardy \& Carlo, 2005; Hart et al., 1998; Padilla-Walker \& Carlo, 2014). Therefore, we chose to study prosocial behavior toward strangers, as it appears to be most analogous to Lerner and colleagues' (2015) PYD perspective (e.g., a form of community contribution). Taking target(s) into account when studying adolescent prosocial behavior uncovers nuances in prosociality and relations with other important features of development, such as intentional self-regulation. The current study therefore aligns with dimensionality-specific efforts to better understand adolescents' prosocial behavior.

\subsection{The current study}

Framed in the Lerner and colleagues' (2015) PYD perspective and relevant empirical work (e.g., Bowers et al., 2011), the purpose of this study was to assess longitudinal, potentially bidirectional relations between intentional self-regulation and prosocial behavior toward strangers from age 12 to age 18. As aforementioned, findings have the potential to critique and advance Lerner and colleagues' (2015) PYD perspective (along with traditional meta-PYD theories), and will likely inform basic and applied efforts focused on understanding and facilitating individual factors that might be used to enhance the probability of adolescents' PYD (as is needed, Lerner et al., 2015). No research to our knowledge tests reciprocal relations between intentional self-regulation and prosocial behavior toward strangers across adolescence, so results offer a particularly salient contribution in terms of understanding individualized PYD processes.

Past work shows that adolescents' sex is related to initial levels of both self-regulation and prosocial behavior (girls are advantaged in both constructs, Böhm, Smedler, \& Forssberg, 2004; Padilla-Walker \& Christensen, 2011), though sex does not necessarily 
moderate growth in or relations between these constructs and other aspects of positive youth development (Fu, Padilla-Walker, \& Brown, 2017; Raffaelli, Corckett, \& Shen, 2005). As such, we anticipated that girls would report higher initial levels of intentional self-regulation and prosocial behavior toward strangers than boys.

\subsubsection{Hypotheses}

We made several additional hypotheses. First, we expected higher levels of intentional self-regulation would be associated with higher levels of prosocial behavior toward strangers across time. Second, we hypothesized higher levels of prosocial behavior toward strangers would be associated with higher levels of intentional self-regulation over time. Third, we expected intentional self-regulation would be more strongly associated with prosocial behavior than the reverse. This hypothesis is rooted in the structure of Lerner and colleagues' (2015) PYD perspective and accompanying empirical work, which repeatedly emphasize the role of intentional self-regulation as a personal asset that is responsible for motivating positive decision making (Gestsdottir \& Lerner, 2008), such as choosing to assist a stranger (Lerner et al., 2002; Lewin-Bizan et al., 2010).

\section{Method}

\subsection{Participants}

Participants for this study were taken from the Flourishing Families Project $(n=500)$. At the initial sampling point, participants were between the ages of 10 and $13\left(M_{\text {age }}=12.15\right.$ years). Fifty-two percent of participants were female and $48 \%$ were male. Approximately $77 \%$ of participants came from two-parent families and $23 \%$ came from single-parent families. Approximately $78 \%$ of participants were European American, 8\% were African American, less were Hispanic (2\%) or Asian American (.5\%), and 12\% identified as multi-ethnic. In terms of parental education, $49.4 \%$ of mothers and $70.63 \%$ of fathers had a bachelor's degree or higher. Per year, $14.4 \%$ of the sample made less than $\$ 25,000,26.2 \%$ made between $\$ 25,000$ and $\$ 50,000,25 \%$ made between $\$ 50,000$ and $\$ 75,000,18.4 \%$ made between $\$ 75,000$ and $\$ 100,000,11.3 \%$ made between $\$ 100,000$ and $\$ 150,000$, and $4.7 \%$ made more than $\$ 150,000$. The average annual income of participants in our sample was approximately $\$ 70,000$ per year at the initial sampling point.

\subsection{Procedures}

Participant families for the Flourishing Families Project were selected from a Northwestern city in the United States and initially participated in the study during Summer 2007. Families were interviewed in their home for the first 5 years of data collection, and via the Internet over the next 5 years of data collection, ending in 2016. Families were primarily recruited using a purchased national telephone survey database (Polk Directories/InfoUSA). All families with a child between the ages of 10 and 13 living within target census tracts were deemed eligible to participate in the Flourishing Families Poject. Of the 692 eligible families contacted, 423 agreed to participate, resulting in a $61 \%$ response rate. In an attempt to more closely mirror the demographics of the local area, a limited number of families were recruited into the study by other means (e.g., referrals, fliers; $\mathrm{n}=77,15 \%$ ), which increased the socialeconomic and ethnic diversity of the sample. Over the course of the project, the attrition rate was minimal $(<10 \%)$.

\subsubsection{Data restructuring}

Because of the large age range at the initial sampling point, data were restructured by age, so that at the first data point, all participants were approximately 10 years old; at the second, 11 years old; at the third, 12 years old; and so on. Restructuring the data by age rather than wave yields clear interpretations of findings (i.e., findings that are age specific, which are of interest to developmental scholars). Because of the several year age range (i.e., 10-14 years), at the initial sampling point in the original (wave) dataset, not all participants were sampled when they were 10,11,12, or 13 years old and therefore there is more missing data at these earlier ages in the restructured age data. In the current study, we chose to use the restructured age data when youth were 12 $\left(M_{\text {age }}=12.15\right), 14\left(M_{\text {age }}=13.98\right), 16\left(M_{\text {age }}=15.99\right)$, and $18\left(M_{\text {age }}=18.03\right)$ years old; from this point forward we will refer to these as Time 1, Time 2, Time 3, and Time 4, respectively. The age at Time 1 (i.e., 12 years) was chosen because (a) youth this age are more likely to experience adolescent-specific transitions, as opposed to younger 10-11 year-old youth (Spear, 2000a 200b); and (b) this was the youngest age group available with enough present data to justify the complexity of our analytic approach. We chose to include a 2-year lag between time points in our study, in order to assess whether relations between variables were sustained over a prolonged period. Thus, we are confident that any findings that emerge across a two-year lag are relatively enduring and meaningful.

\subsection{Measures}

Both measures used in this paper were calculated and used as mean scales. Higher coded values represented higher levels of each construct. Although latent constructs representing intentional self-regulation and prosocial behavior toward strangers, respectively, were not used due to the already complex nature of our analytic approach (Hamaker, Kuiper, \& Grasman, 2015), measurement invariance was tested for to ensure consistency in the qualitative interpretation of both constructs across the four measurement points of this study.

\subsubsection{Intentional self-regulation}

An adapted (shortened) intentional self-regulation measure (Novak \& Clayton, 2001) assessed participants' ability to set and 
attain goals. Adolescent participants self-reported on 4 items including, "Once I have a goal, I make a plan to reach it". Cronbach's alpha coefficients ranged from .70-.77 across the three points. Responses were gathered on a 4-point Likert scale ranging from 1 (never true) to 4 (always true). Invariance analyses indicated this measure was not invariant across Times $1,2,3$, and 4 . Specifically, the first factor loading was invariant across Time 1 and Time 2, and separately across Time 3 and Time 4. The second factor loading was invariant across Time 1 and Time 3, but was unique at Time 2 and Time 4, respectively. And the third factor loading was invariant at Time 1 and Time 4, but was equivalent at Time 2 and Time 3, respectively.

\subsubsection{Prosocial behavior toward strangers}

The self-report Inventory of Strengths (Peterson \& Seligman, 2004) was used to measure adolescents' perceptions of their own general kindness and generosity toward strangers. In terms of how much they disagreed or agreed with statements about themselves, adolescent participants responded to questions like "I voluntarily help those I do not know" and "I help those I do not know, even if it is not easy for me" ( $\alpha=.84-.88$ across the four time points). Responses on this 5-item subscale were collected on a 5-point Likert-type scale, ranging from 1 (not like me at all) to 5 (very much like me). Aligned with previous studies that use the same measure and dataset (Padilla-Walker et al., 2015a), the results of invariance analyses revealed prosocial behavior toward strangers was weakly/partially invariant across Time 1, 2, 3, and 4 (i.e., nearly all factor loadings could be constrained to be equal across time without significantly decreasing model fit; Dimitrov, 2010; Dyer, 2015) except for one item at Time 2, and three items at Time 4.

\subsubsection{Sex}

Participants indicated whether they identified as female (coded as " 0 ") or male (coded as "1").

\section{Results}

\subsection{Descriptive statistics and correlations}

Descriptive statistics were conducted in order to assess characteristics of the sample and preliminary relations between variables. Means, standard deviations, and correlations for each continuous study variable (i.e., intentional self-regulation and prosocial behavior toward strangers) at each time point were estimated and are represented in Table 1. At each Time point, intentional selfregulation and prosocial behavior toward strangers were positively associated. Intentional self-regulation at Time 1, 2, 3, and 4 were highly intercorrelated, as were prosocial behavior toward strangers at Time 1, 2, 3, and 4.

\subsection{Missing data and attrition analyses}

At later waves in the Flourishing Families Project, planned missingness was incorporated into the study design (Little, 2013), which resulted in manageable amounts of missing data. Data from the Flourishing Families Project remained MCAR because the missingness was totally random. After the dataset was reorganized from wave to age, the principal investigators of the study used a single imputation to fill in some missing values associated with the planned missingness design. This single data imputation was used to fill in values for study variables at Time 3 (i.e., age 16) and Time 4 (i.e., age 18). After this single data imputation was performed, remaining missing values were coded uniformly (i.e., as “."). We assessed the nature of missing data by running a series of T-tests to determine whether there were significant differences on key study variables (i.e., prosocial behavior) based on whether or not data were fully present or missing to some degree. We followed the procedures outlined by Rubin (1976). A dichotomous variable representing missingness was generated and the values were coded as either "0" (no missing data on a study variable across all time points) or " 1 " (at least one missing value or more on a given study variable across all time points). Next, this generated dichotomous variable (i.e., "missingness") was used as a predictor in a series of T-tests in order to ascertain whether it significantly distinguished between observed scores on each key study variable (i.e., prosocial behavior and intentional self-regulation at Times 1, 2, 3, and 4). Thus, 8 total T-tests were conducted. These confirmed that data on all intentional self-regulation variables were missing at random (not MNAR). More specifically, there were no significant differences between reported levels of intentional self-regulation based on

Table 1

Bivariate correlations between study variables.

\begin{tabular}{|c|c|c|c|c|c|c|c|c|}
\hline & 1. & 2. & 3. & 4. & 5. & 6. & 7. & 8. \\
\hline 1. Intentional SR 12 & - & & & & & & & \\
\hline 2. Intentional SR 14 & $.45^{* * *}$ & - & & & & & & \\
\hline 3. Intentional SR 16 & $.34 * * *$ & $.47^{* * *}$ & - & & & & & \\
\hline 4. Intentional SR 18 & $.29^{* * *}$ & $.35^{* * *}$ & $.49^{* * *}$ & - & & & & \\
\hline 5. PB strangers 12 & $.47 * * *$ & $.36^{* * *}$ & $.29 * * *$ & $.15^{* *}$ & - & & & \\
\hline 6. PB strangers 14 & $.35^{* * *}$ & $.48^{* * *}$ & $.27^{* * *}$ & $.20 * * *$ & $.56 * * *$ & - & & \\
\hline 7. $\mathrm{PB}$ strangers 16 & $.16^{* * *}$ & $.29 * * *$ & $.29^{* * *}$ & $.26^{* * *}$ & $.26^{* * *}$ & $.61^{* * *}$ & - & \\
\hline 8. PB strangers 18 & $.12^{*}$ & $.21^{* * *}$ & $.19 * * *$ & $.23^{* * *}$ & $.31^{* * *}$ & $.52^{* * *}$ & $.54 * * *$ & - \\
\hline $\mathrm{M}(\mathrm{SD})$ & $3.05(.57)$ & $3.02(.62)$ & $3.03(.66)$ & $3.12(.62)$ & $3.21(.75)$ & $3.18(.74)$ & $3.46(.76)$ & $3.69(.75)$ \\
\hline Range & $1.5-4$ & $1-4$ & $1-4$ & $1.25-4$ & $1.33-4.89$ & $1-5$ & $1.22-5$ & $1.22-5$ \\
\hline
\end{tabular}

Note. SR $=$ self-regulation, $\mathrm{PB}=$ prosocial behavior. ${ }^{*} \mathrm{p}<.05, * * \mathrm{p}<.01, * * \mathrm{p}<.001$. 
missingness at Times 1, 2, and 4 (i.e., ages 12, 14 and 18). Conversely, results indicated missingness was related to prosocial behavior toward strangers at Times 1, 2, and 4 (i.e., ages 12, 14, and 18) so Maximum Likelihood (ML) estimation was used when conducting analyses, which is typical when estimating models with data that are not MCAR within a structural equation modeling framework (Enders \& Bandalos, 2001; Muthén, Kaplan, \& Hollis, 1987). Please note that there are no missing data results for intentional selfregulation or prosocial behavior toward strangers at Time 3 (age 16) because there were no missing data on these variables at this time point, in part due to the restructuring of the data and subsequent data imputation.

\subsection{Random intercepts cross-lagged panel model}

A random intercepts cross-lagged panel model (RI-CLPM, Hamaker et al., 2015) was estimated in Mplus v. 8.1 software (Muthén \& Muthén, 1998-2017) in order to assess bidirectional relations between intentional self-regulation and prosocial behavior toward strangers. This type of model includes the specification of autoregressive paths as well as random intercept factors (for each construct across time), which account for inter-individual (i.e., trait-like, between-person) stability in these constructs over time. The remaining cross-lagged paths represent intra-individual (within-person) variation in intentional self-regulation and prosocial behavior toward strangers over time. Therefore, estimating RI-CLPM's allow researchers to correctly distinguish and interpret intra- and inter-individual differences and to avoid drawing "erroneous conclusions regarding the presence, predominance, and sign of causal influences" (pg. 102), which has been done in previous studies that estimate simple cross-lagged panel models (see Hamaker and colleagues' (2015) work for additional details regarding the specification of the RI-CLPM). Specific to our data, we constrained random intercept loadings, covariances, stability coefficients, and cross-lagged paths, respectively, to be equal to one another across time (when doing so did not significantly decrease model fit) in order to prioritize parsimony and increase the interpretability of our model across adolescence.

\subsubsection{Findings}

Results of the RI-CLPM revealed the model fit the data well, $\chi^{2}(25)=84.90, p<.001$, CFI $=.95$, RMSEA $=.07$, [.05-.09]) (Little, 2013). Sex was not significantly associated with either intentional self-regulation $(\beta=.01, p=.884)$ or prosocial behavior toward strangers $(\beta=.02, p=.666)$ at the initial time point (age 12). Intentional self-regulation was somewhat stable over time (i.e., standardized autoregressive coefficients ranged from .24-.29), as was prosocial behavior toward strangers (i.e., standardized autoregressive coefficients ranged from .24-.40). In terms of intra-individual (within-person) effects, intentional self-regulation at age 12 was significantly associated with prosocial behavior toward strangers at age 14, but intentional self-regulation was not significantly associated with prosocial behavior toward strangers from age 14 to 16 or from 16 to 18 , respectively. On the other hand, prosocial behavior toward strangers was significantly associated with intentional self-regulation across adolescence (i.e., from age 12 to 14,14 to 16 , and from 16 to 18, respectively). See Fig. 2 for associated standardized coefficients and a visual representation of relations between intentional self-regulation and prosocial behavior toward strangers.

\section{Discussion}

Couched within Lerner and colleagues' (2015) PYD perspective, the purpose of the current study was to assess intra-individual bidirectional relations between intentional self-regulation and prosocial behavior toward strangers from age 12 to age 18 . Results revealed that intentional self-regulation and prosocial behavior toward strangers were bidirectionally related during early adolescence (i.e., from age 12 to 14). Unique unidirectional associations were found during middle to late adolescence (i.e., from age 14 to 16 , and from age 16 to 18), where prosocial behavior toward strangers facilitated intentional self-regulation, but intentional self-regulation did not drive the development of prosocial behavior toward strangers. Given the two-year lag between each time point and the fact that previous levels of each variable were taken into account in analyses, the results of this study remain notable despite somewhat small effect sizes, and provide a foundation for future researchers and intervention work concerned with adolescents' PYD. Findings also have important implications for studying prosocial behavior from specific (e.g., Lerner et al., 2015) and global (Damon, 2004; Larson, 2000) PYD perspectives. It is worth noting that our measure of prosocial behavior in this study tapped adolescents' selfperceptions of their own prosocial tendencies toward strangers, rather than observed prosocial behavioral frequencies; with this in mind, we carefully interpret our results in light of extant empirical work.

\subsection{Bidirectional associations}

In line with Lerner and colleagues' PYD perspective (2002; 2015) and accompanying hypotheses, results indicated that from age 12 to 14, higher levels of intentional self-regulation were associated with increased self-perceptions of adolescents' prosocial behavior toward strangers; and greater perceived engagement in prosocial behavior toward strangers was associated with higher levels of intentional self-regulation. These findings strengthen and extend past unidirectional research that assesses prosocial behavior using peer nominations (Eisenberg et al., 1996) or more general measures (Lerner et al., 2015). This evidence for bidirectionality additionally demonstrates the iterative plasticity of the PYD process specifically during early adolescence, in that individualized (i.e., intra-individual; Hamaker et al., 2015) positive features of development tend to facilitate additional positive developmental features (Lerner et al., 2015; Masten \& Cicchetti, 2010). More specifically, findings imply that young adolescents' effective implementation of intentional self-regulation predisposes youth to view themselves as helpful toward strangers (i.e., as helpful in high-cost contexts; Lewin-Bizan et al., 2010; Padilla-Walker \& Carlo, 2014); and perceiving one's self as helpful toward strangers engages and strengthens 


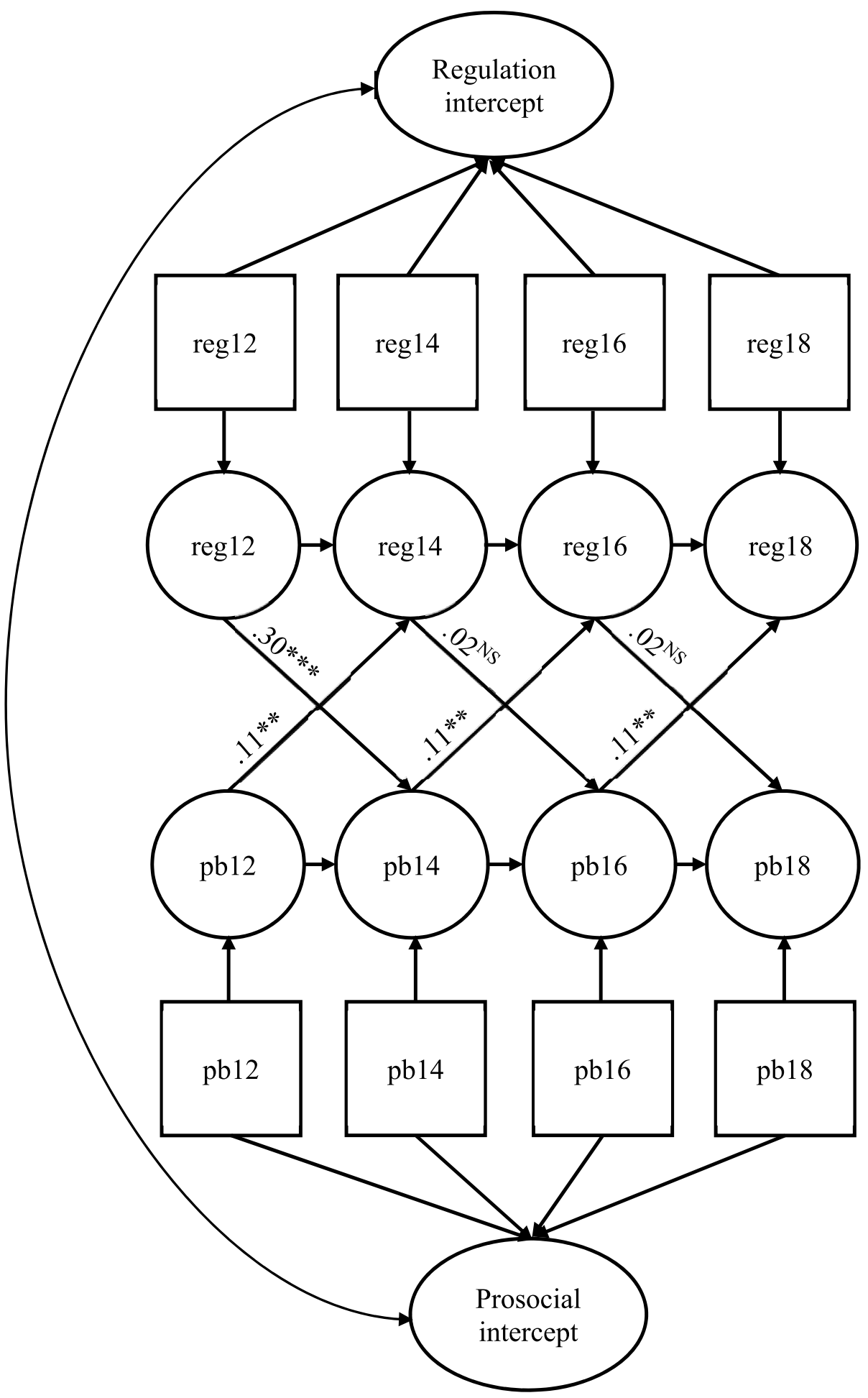

Fig. 2. Bidirectional associations between intentional self-regulation and prosocial behavior toward strangers from age 12 to age 18 . Note. Covariances between single-item latent variables at age 12, covariances between innovation terms at age 12, latent error variances at all time points, and endogenous error correlations between constructs at ages 14, 16, and 18 are not depicted in the interest of parsimony. Stability coefficients are reported in text. Sex/gender was employed as a control variable but is not depicted in the figure.

NS $=$ non-significant; $* * p<.01 ; * * p<.001$. 
intentional self-regulatory skills across time (Lerner et al., 2002, 2015) as youth seek to continually help those they do not know. Thus, having strong personal assets (e.g., intentional self-regulation) and viewing one's self as contributing meaningfully to one's socioemotional contexts (e.g., engaging in prosocial behavior toward strangers) promote each other during early adolescence (Lerner et al., 2015).

Additional interdisciplinary research findings complement these explanations for bidirectional associations between intentional self-regulation and self-perceptions of prosocial behavior toward strangers. For instance, some motivation-related research evidences that youth who are intentionally self-regulated are predisposed toward and therefore inclined to engage in, or perhaps view themselves as engaging in, similarly functional actions like prosocial behavior toward strangers (Bandura, 1991; Bandura \& Simon, 1977). More work in the moral development field indicates that adolescents who use their intentional self-regulation to actively create, maintain, and achieve prosocial goals will be more likely to engage in and perceive themselves as engaging in helpful, otheroriented behaviors (Hardy \& Carlo, 2005; Hart et al., 1998). However, it is just as probable that adolescents who view themselves as engaging in prosocial behavior toward strangers will seek to create prosocial goals, and subsequently implement their intentional self-regulation. Accordingly, studies indicate individuals' regulatory capacities can be strengthened through repeated use (Muraven, 2010; Muraven \& Baumeister, 2000), so perhaps self-perceptions of prosocial engagement cue self-regulatory capacities, which are further developed over time. Several of these explanations rely on variables that were unmeasured in the current study. Therefore, future researchers should carefully consider and empirically test each explanation for bidirectionality between these constructs in order to importantly build upon the results of the current study.

\subsubsection{The developmental salience of early adolescence}

Bidirectional associations between self-regulation and perceptions of prosocial behavior did not extend into middle or late adolescence (i.e., from age 14 to age 18), suggesting that early adolescence may be a unique time during which these constructs influence each other. During early-to-middle adolescence (i.e., ages 12-14 in the current study), research indicates youth are simultaneously faced with the onset of biological, physical (Bitar, Vernet, Coudert, \& Vermorel, 2000), neural/cognitive (Sisk \& Foster, 2004), emotional, and social (Hardy et al., 2002; Patton \& Viner, 2007) changes, transitions, and stimulus. For instance, adolescents' bodies and minds mature as youth begin attending an unfamiliar and larger school, while social norms and peer interactions increase in complexity. It is possible that young adolescents in particular set social goals (e.g., develop friendships) and accomplish these goals by engaging in prosocial behavior toward strangers (Li \& Wright, 2014). Doing so would help satisfy the salient need for connection that adolescents experience as they undergo developmental changes, transitions, and stimulus (Laursen \& Hartl, 2013; Vieno, Santinello, Pastore, \& Perkins, 2007). Additionally, young adolescents who engage in, or perceive themselves as engaging in, prosocial behavior toward strangers likely accumulate socioemotional resources (e.g., positive views of the self, emotion capacities) that are critical during this period, which can be invested in the development and attainment of relevant goals (e.g., academic achievement, sports performance, further connection with others, etc.). Thus, intentional self-regulation and prosocial behavior toward strangers develop and change during early adolescence, potentially influencing each other in unique ways than at earlier or later points in development. Scholars might further investigate bidirectional associations between self-regulation and prosocial behavior (both perceptions and behavioral frequencies) at earlier and later time points (i.e., childhood, early adulthood), in order to elucidate whether self-regulation and prosocial behavior are uniquely influential on each other during early adolescence, or whether these associations persist during other developmental periods.

\subsection{Unidirectional associations}

Somewhat surprisingly, across middle (i.e., age 14 to 16) and late (i.e., age 16 to 18) adolescence, earlier perceptions of one's self as prosocial toward strangers facilitated later intentional self-regulation, though earlier intentional self-regulation did not drive the development of later self-perceptions of prosocial behavior toward strangers. These findings in part support Lerner and colleagues' (2002; 2015) PYD perspective, which argues prosociality is best categorized as a form of contribution, rather than a person $\leftarrow \rightarrow$ context exchange in itself or an indicator of PYD (Damon, 2004; Larson, 2000). If this is the case, it is logical that adolescents' selfperceptions of prosocial behavior toward strangers are directly associated with the development of intentional self-regulation because contribution helps maximize individuals' personal assets; whereas intentional self-regulation may not directly influence the development of prosocial behavior because this association is theoretically indirect through the "caring" PYD indicator (e.g., moral emotions like empathy, sympathy, perspective taking, guilt, etc.). More empirical evidence is needed to test these process-specific assertions.

In addition to these theoretical implications, the current study also has empirical and practical implications for scholars and field workers alike. For researchers, findings confirm the particularly adaptive value of self-perceptions of one's self as prosocial toward strangers (Hardy \& Carlo, 2005; Hart et al., 1998; Padilla-Walker \& Carlo, 2014). Our findings are in line with findings from past research that show prosociality (frequencies and self-perceptions) is both protective against negative outcomes (Eccles \& Barber, 1999; Padilla-Walker et al., 2015b) and facilitative of positive ones (Caprara, Barbaranelli, Pastorelli, Bandura, \& Zimbardo, 2000; Wentzel, 1993). As such, future researchers should not fail to explore the role of prosocial behavior toward strangers within and outside of a PYD framework, in order to best understand the behaviors that help youth develop positively throughout adolescence and during the transition to adulthood. Relatedly, the findings of this study suggest practitioners might consider involving adolescents in ample opportunities to engage in prosocial behavior toward strangers, in order to foster a sense of individual helpfulness, strengthen adolescents' intentional self-regulatory capacities, and possibly promote thriving over time. 


\subsection{Lack of measurement invariance}

Ensuring measurement equivalence within constructs across time is a prerequisite to conducting RI-CLPM's (Hamaker et al., 2015) and drawing appropriate conclusions about patterns of longitudinal relations between constructs (Little, 2013). It is therefore critical to point out that our measure of intentional self-regulation was found to be invariant over time, which means that current elucidations of unidirectional findings and non-findings should be interpreted and applied with caution. In particular, this is because measurement invariance across time implies there is qualitative, rather than quantitative change occurring, which equates to a lack of consistency in the meaning of a particular construct and its relations with other constructs across time (Widaman, Ferrer, \& Conger, 2010). Therefore, findings that indicate intentional self-regulation and prosocial behavior toward strangers are bidirectionally related during early adolescence but not during middle and late adolescence may be based on the fact that self-regulation has varying qualitative meanings across the course of adolescence. There are several arguments that support this alternative explanation. For instance, it is possible that intentional self-regulation is a cognitive process that shifts in meaning as adolescents encounter developmentally-salient experiences regarding their personal volition and agency (Wehmeyer \& Shogren, 2017; Widaman et al., 2010). Along these lines, it may even be expected that self-regulation is invariant over the course of adolescence, as the cognitive reorganization that occurs during adolescence (Dahl, 2004) may predispose adolescents to differentially interpret the meaning and role of intentional self-regulation over time. Taken together, future researchers should further explore the phenomenon of invariance in intentional self-regulation across adolescence, in order to better assess its nature and the consistency of relations with other developmental outcomes including prosocial behavior toward strangers.

\subsection{Limitations and future directions}

Additional limitations of the current study exist. For instance, the sample was disproportionately White and came from high SES and two-parent families. Because of the limited variability in these constructs, they were not controlled for in the current study. As such, the results of this study should not be generalized to all populations and researchers should seek to analyze links between targets of prosocial behavior and dimensions of self-regulation in more diverse samples. In addition, we found no differences in females' and males' initial levels of intentional self-regulation and self-perceptions of prosocial behavior, despite past research findings that did uncover sex differences in these constructs (Böhm et al., 2004; Padilla-Walker \& Christensen, 2011). Additional investigation is therefore needed to strengthen and explain the current findings. It is also worth noting that this study utilized selfreport, close-ended survey data. Although these methods have been used consistently in adolescent research, scholars have also noted the rich contribution of other-report questionnaires (e.g. teacher or parent reports), observational coding, qualitative data, and experimental methods (e.g., economic games; Shariff \& Norenzayan, 2007). Therefore, future research should aim to analyze links between self-regulation and prosocial behavior while using additional or multiple methods (Lerner et al., 2015). Finally, our measure of prosocial behavior tapped adolescents' self-perceptions of their own prosocial behavior, rather than the frequencies of their prosocial actions. Although this operationalization of prosocial behavior is not unique to the current study, and many scholars assert measures of behavioral frequencies of prosocial behavior have clear limitations (El Mallah, 2019), researchers should be increasingly aware of the limitations of extant prosocial behavior measures, and should seek to correctly interpret findings based on the prosocial behavior measurement that is employed in a given study.

Despite these limitations, the findings of the current study are salient for theorists, researchers, and field workers alike. Results revealed adolescents' intentional self-regulation and perceptions of prosocial behavior toward strangers influence one another from early to middle adolescence, and that adolescents' self-perceptions of prosocial behavior toward strangers contributes to increases in intentional self-regulatory development during middle and late adolescence. Findings suggest early adolescence may be a particularly plastic developmental period, viewing oneself as prosocial toward strangers can promote intentional self-regulation, and involving adolescents in prosocial behavior toward strangers is a priority. The influential role of self-perceptions and behavioral frequencies of prosocial behavior on the development of self-regulatory capacities is rarely studied in the current literature. However, it is important to further illuminate how these constructs along with other purposeful actions inform adolescents' personal assets, adaptive developmental regulations, PYD, contribution, and adjustment. Taken together, we hope this study will serve as a springboard for future research and intervention work that seeks to support and extend the PYD perspective, along with programs focused on adolescents' self-regulation, prosociality, and additional aspects of PYD.

\section{References}

Arnett, J. J. (2000). Emerging adulthood: A theory of development from the late teens through the twenties. American Psychologist, 55(5), 469-480. https://doi.org/10. 1037//0003-066X.55.5.469.

Ary, D. V., Duncan, T. E., Biglan, A., Metzler, C. W., Noell, J. W., \& Smolkowski, K. (1999). Development of adolescent problem behavior. Journal of Abnormal Child Psychology, 27(2), 141-150.

Bandura, A. (1991). Social cognitive theory of self-regulation. Organizational Behavior and Human Decision Processes, 50(2), $248-287$.

Bandura, A., \& Simon, K. M. (1977). The role of proximal intentions in self-regulation of refractory behavior. Cognitive Therapy and Research, 1(3), 177-193.

Binswanger, H. (1991). Volition as cognitive self-regulation. Organizational Behavior and Human Decision Processes, 50(2), 154-178. https://doi.org/10.1016/07495978(91)90019-P.

Bitar, A., Vernet, J., Coudert, J., \& Vermorel, M. (2000). Longitudinal changes in body composition, physical capacities and energy expenditure in boys and girls during the onset of puberty. European Journal of Nutrition, 39(4), 157-163.

Boekaerts, M., \& Corno, L. (2005). Self-regulation in the classroom: A perspective on assessment and intervention. Applied Psychology, 54(2), $199-231$.

Böhm, B., Smedler, A. C., \& Forssberg, H. (2004). Impulse control, working memory and other executive functions in preterm children when starting school. Acta 
Paediatrica, 93(10), 1363-1371. https://doi.org/10.1111/j.1651-2227.2004.tb02938.x.

Bowers, E. P., Gestsdottir, S., Geldhof, G. J., Nikitin, J., \& von Eye, A. (2011). Developmental trajectories of intentional self regulation in adolescence: Implications for positive and problematic development among diverse youth. Journal of Adolescence, 34, 1193-1206. https://doi.org/10.1016/j.adolescence.2011.07.006.

Caprara, G. V., Barbaranelli, C., Pastorelli, C., Bandura, A., \& Zimbardo, P. G. (2000). Prosocial foundations of children's academic achievement. Psychological Science, 11(4), 302-306.

Card, N. A., \& Little, T. D. (2006). Proactive and reactive aggression in childhood and adolescence: A meta-analysis of differential relations with psychosocial adjustment. International Journal of Behavioral Development, 30(5), 466-480. https://doi.org/10.1177/0165025406071904.

Cavadel, E. W., Kauff, J. F., Anderson, M. A., McConnell, S., \& Derr, M. (2016). Self-regulation and goal attainment: A new perspective for employment programs (No. e49aff23628f45bd847fd2e869c107b0). Mathematica Policy Research.

Conway, P., \& Peetz, J. (2012). When does feeling moral actually make you a better person? Conceptual abstraction moderates whether past moral deeds motivate consistency or compensatory behavior. Personality and Social Psychology Bulletin, 38(7), 907-919. https://doi.org/10.1177/0146167212442394.

Dahl, R. E. (2004). Adolescent brain development: a period of vulnerabilities and opportunities: Keynote address. Annals of the New York Academy of Sciences, 1021(1), 1-22. https://doi.org/10.1106/annals.1308.001.

Damon, W. (2004). What is positive youth development? The Annals of the American Academy of Political and Social Science, 591(1), 13-24. https://doi.org/10.1177/ 0002716203260092

DeWall, C. N., Baumeister, R. F., Gailliot, M. T., \& Maner, J. K. (2008). Depletion makes the heart grow less helpful: Helping as a function of self-regulatory energy and genetic relatedness. Personality and Social Psychology Bulletin, 34(12), 1653-1662. https://doi.org/10.1177/0146167208323981.

Dimitrov, D. M. (2010). Testing for factorial invariance in the context of construct validation. Measurement and Evaluation in Counseling and Development, 43(2), 121-149. https://doi.org/10.1177/0748175610373459.

Dyer, W. J. (2015). The vital role of measurement equivalence in family research. Journal of Family Theory \& Review, 7(4), 415-431. https://doi.org/10.1111/jftr. 12115.

Eccles, J. S., \& Barber, B. L. (1999). Student council, volunteering, basketball, or marching band: What kind of extracurricular involvement matters? Journal of Adolescent Research, 14(1), 10-43. https://doi.org/10.1177/0743558499141003.

Eisenberg, N., Fabes, R. A., Karbon, M., Murphy, B. C., Wosinski, M., Polazzi, L., et al. (1996). The relations of children's dispositional prosocial behavior to emotionality, regulation, and social functioning. Child Development, 67(3), 974-992. https://doi.org/10.1111/j.1467-8624.1996.tb01777.x.

Eisenberg, N., Spinrad, T. L., \& Knafo-Noam, A. (2015). Prosocial development. In M. E. Lamb, R. M. Lerner, M. E. Lamb, \& R. M. Lerner (Vol. Eds.), (7th ed.), Socioemotional processes: Vol. 3. Handbook of child psychology and developmental science (pp. 610-656). Hoboken, NJ, US: John Wiley \& Sons Inc.

El Mallah, S. (2019). Conceptualization and measurement of adolescent prosocial behavior: Looking back and moving forward. Journal of Research on Adolescence. https://doi.org/10.1111/jora.12476*****).

Enders, C. K., \& Bandalos, D. L. (2001). The relative performance of full information maximum likelihood estimation for missing data in structural equation models. Structural Equation Modeling, 8(3), 430-457.

Flook, L., Goldberg, S. B., Pinger, L., \& Davidson, R. J. (2015). Promoting prosocial behavior and self-regulatory skills in preschool children through a mindfulnessbased kindness curriculum. Developmental Psychology, 51(1), 44-51. https://doi.org/10.1037/a0038256.

Fu, X., Padilla-Walker, L. M., \& Brown, M. N. (2017). Longitudinal relations between adolescents' self-esteem and prosocial behavior toward strangers, friends and family. Journal of Adolescence, 57, 90-98. https://doi.org/10.1016/j.adolescence.2017.04.002.

Geldhof, G. J., Bowers, E. P., Boyd, M. J., Mueller, M. K., Napolitano, C. M., Schmid, K. L., et al. (2014). Creation of short and very short measures of the five Cs of positive youth development. Journal of Research on Adolescence, 24(1), 163-176. https://doi.org/10.1111/jora.12039.

Gestsdottir, S., \& Lerner, R. M. (2008). Positive development in adolescence: The development and role of intentional self-regulation. Human Development, 51(3), 202-224.

Gilchrist, L. D. (2017). Social competence in adolescence. In S. P. Schinke (Ed.). Behavioral methods in social welfare (pp. 61-80). New York, NY: Routledge.

Güroğlu, B., van den Bos, W., \& Crone, E. A. (2014). Sharing and giving across adolescence: An experimental study examining the development of prosocial behavior Frontiers in Psychology, 5, 1-13. https://doi.org/10.3389/fpsyg.2014.00291.

Hamaker, E. L., Kuiper, R. M., \& Grasman, R. P. (2015). A critique of the cross-lagged panel model. Psychological Methods, 20(1), 102-116. https://doi.org/10.1037/ a0038889.

Hardy, C. L., Bukowski, W. M., \& Sippola, L. K. (2002). Stability and change in peer relationships during the transition to middle-level school. The Journal of Early Adolescence, 22(2), 117-142.

Hardy, S. A., \& Carlo, G. (2005). Identity as a source of moral motivation. Human Development, 48(4), 232-256. https://doi.org/10.1159/000086859.

Hart, D., Atkins, R., \& Ford, D. (1998). Urban America as a context for the development of moral identity in adolescence. Journal of Social Issues, 54(3), 513-530.

Jelicic, H., Bobek, D. L., Phelps, E., Lerner, R. M., \& Lerner, J. V. (2007). Using positive youth development to predict contribution and risk behaviors in early adolescence: Findings from the first two waves of the 4-H Study of Positive Youth Development. International Journal of Behavioral Development, 31(3), 263-273. https://doi.org/10.1177/0165025407076439.

Larson, R. W. (2000). Toward a psychology of positive youth development. American Psychologist, 55(1), 170-183. https://doi.org/10.1037//0003-066X,55.1.170.

Laursen, B., \& Hartl, A. C. (2013). Understanding loneliness during adolescence: Developmental changes that increase the risk of perceived social isolation. Journal of Adolescence, 36(6), 1261-1268. https://doi.org/10.1016/j.adolescence.2013.06.003.

Lerner, R. M., Brentano, C., Dowling, E. M., \& Anderson, P. M. (2002). Positive youth development: Thriving as the basis of personhood and civil society. New Directions for Youth Development, (95), 11-34 2002.

Lerner, R. M., \& Busch-Rossnagel, N. A. (1981). Individuals as producers of their development: Conceptual and empirical bases. In R. M. Lerner, \& N. A. Rossnagel (Eds.). Individuals as producers of their development: A life-span perspective (pp. 1-36). New York, NY: Academic Press.

Lerner, R. M., Lerner, J. V., Almerigi, J. B., Theokas, C., Phelps, E., Gestsdottir, S., et al. (2005). Positive youth development, participation in community youth development programs, and community contributions of fifth-grade adolescents: Findings from the first wave of the 4-H study of positive youth development. The Journal of Early Adolescence, 25(1), 17-71. https://doi.org/10.1177/0272431604272461.

Lerner, R. M., Lerner, J. V., Bowers, E. P., \& Geldhof, G. J. (2015). Positive youth development and relational-developmental-systems. In R. M. Lerner, W. F. Overton, \& P. C. M. Molenaar (Eds.). Handbook of child psychology and developmental science (pp. 1-45). . https://doi.org/10.1002/9781118963418.childpsy116 (1).

Lerner, R. M., \& Walls, T. (1999). Revisiting individuals as producers of their development: From dynamic interactionism to developmental systems. In J. Brandtstädter, \& R. M. Lerner (Eds.). Action \& self-development: Theory and research through the life span (pp. 3-36). Thousand Oaks, CA: Sage Publications Inc. https://doi.org/10.4135/9781452204802.n1

Lerner, R. M., Wang, J., Hershberg, R. M., Buckingham, M. H., Harris, E. M., Tirrell, J., et al. (2017). Positive youth development among minority youth: A relational developmental systems model. In N. J. Cabrera, \& B. Leyendecker (Eds.). Handbook on positive development of minority children and youth (pp. 5-17). Netherlands: Springer.

Lewin-Bizan, S., Bowers, E. P., \& Lerner, R. M. (2010). One good thing leads to another: Cascades of positive youth development among American adolescents. Development and Psychopathology, 22(4), 759-770.

Little, T. D. (2013). Longitudinal structural equation modeling. New York, NY: Guilford Press.

Li, Y., \& Wright, M. F. (2014). Adolescents' social status goals: Relationships to social status insecurity, aggression, and prosocial behavior. Journal of Youth and Adolescence, 43(1), 146-160. https://doi.org/10.1007/s10964-013-9939-z.

Martinsson, P., Myrseth, K. O. R., \& Wollbrant, C. (2010). Reconciling pro-social vs. selfish behavior: Evidence for the role of self-control (No. 10-003 (R1)). ESMT Working Paper.

Masten, A. S., \& Cicchetti, D. (2010). Developmental cascades. Development and Psychopathology, 22(3), 491-495. https://doi.org/10.1017/S0954579410000222.

McClelland, M. M., Ponitz, C. C., Messersmith, E. E., \& Tominey, S. (2010). Self-regulation: The integration of cognition and emotion. In W. Overton, Vol, \& R. Lerner (Eds.). Handbook of life-span human development: Vol. 1. Cognition, biology and methods (pp. 509-553). Hoboken, NJ: Wiley. https://doi.org/10.1002/ 
9780470880166.hlsd001015.

Mead, N. L., Baumeister, R. F., Gino, F., Schweitzer, M. E., \& Ariely, D. (2009). Too tired to tell the truth: Self-control resource depletion and dishonesty. Journal of Experimental Social Psychology, 45(3), 594-597. https://doi.org/10.1016/j.jesp.2009.02.004.

Muraven, M. (2010). Building self-control strength: Practicing self-control leads to improved self-control performance. Journal of Experimental Social Psychology, 46(2), 465-468. https://doi.org/10.1016/j.jesp.2009.12.011.

Muraven, M., \& Baumeister, R. F. (2000). Self-regulation and depletion of limited resources: Does self-control resemble a muscle? Psychological Bulletin, 126(2), 247-259 I0.I037//0033-2909.126.2.247.

Muraven, M., Baumeister, R. F., \& Tice, D. M. (1999). Longitudinal improvement of self-regulation through practice: Building self-control strength through repeated exercise. The Journal of Social Psychology, 139(4), 446-457.

Muthén, B., Kaplan, D., \& Hollis, M. (1987). On structural equation modeling with data that are not missing completely at random. Psychometrika, 52(3), 431-462.

Muthén, L. K., \& Muthén, B. O. (1998-2017). Mplus user's guide (8th ed.). Los Angeles, CA: Muthén \& Muthén.

Nigg, J. T. (2017). Annual Research Review: On the relations among self-regulation, self-control, executive functioning, effortful control, cognitive control, impulsivity, risk-taking, and inhibition for developmental psychopathology. Journal of Child Psychology and Psychiatry, 58(4), 361-383. https://doi.org/10.1111/ jcpp.12675.

Normandeau, S., \& Guay, F. (1998). Preschool behavior and first-grade school achievement: The mediational role of cognitive self-control. Journal of Educational Psychology, 90(1), 111-121. https://doi.org/10.1037/0022-0663.90.1.111.

Novak, S. P., \& Clayton, R. R. (2001). The influence of school environment and self-regulation on transitions between stages of cigarette smoking: A multilevel analysis. Health Psychology, 20, 196-207. https://doi.org/10.1037/0278-6133.20.3.196.

Overton, W. F. (2013). A new paradigm for developmental science: Relationism and relational-developmental systems. Applied Developmental Science, 17(2), 94-107. https://doi.org/10.1080/10888691.2013.778717.

Overton, W. F., \& Lerner, R. M. (2012). Relational developmental systems: A paradigm for developmental science in the postgenomic era. Behavioral and Brain Sciences, 35(5), 375-376. https://doi.org/10.1017/S0140525X12001082.

Padilla-Walker, L. M., \& Carlo, G. (Eds.). (2014). Prosocial development: A multidimensional approachNew York, NY: Oxford University Press. https://doi.org/10.1093/ acprof:oso/9780199964772.001.0001.

Padilla-Walker, L. M., Carlo, G., \& Memmott-Elison, M. K. (2018). Longitudinal change in adolescents' prosocial behavior toward strangers, friends, and family. Journal of Research on Adolescence, 28(3), 698-710. https://doi.org/10.1111/jora.12362.

Padilla-Walker, L. M., \& Christensen, K. J. (2011). Empathy and self-regulation as mediators between parenting and adolescents' prosocial behavior toward strangers, friends, and family. Journal of Research on Adolescence, 21, 545-551. https://doi.org/10.1111/j.15327795.2010.00695.x.

Padilla-Walker, L. M., Dyer, W. J., Yorgason, J. B., Fraser, A. M., \& Coyne, S. M. (2015a). Adolescents' prosocial behavior toward family, friends, and strangers: A person-centered approach. Journal of Research on Adolescence, 25(1), 135-150. https://doi.org/10.1111/jora.12102.

Padilla-Walker, L. M., Carlo, G., \& Nielson, M. G. (2015b). Does helping keep teens protected? Longitudinal bidirectional relations between prosocial behavior and problem behavior. Child Development, 86(6), 1759-1772. https://doi.org/10.1111/cdev.12411.

Patton, G. C., \& Viner, R. (2007). Pubertal transitions in health. The Lancet, 369(9567), 1130-1139. https://doi.org/10.1016/S0140-6736(07)60366-3.

Peterson, C., \& Seligman, M. E. P. (2004). Character strengths and virtues: A handbook and classification. Washington, DC: Oxford University Press.

Phelps, E., Zimmerman, S., Warren, A. E. A., Jeličić, H., von Eye, A., \& Lerner, R. M. (2009). The structure and developmental course of positive youth development (PYD) in early adolescence: Implications for theory and practice. Journal of Applied Developmental Psychology, 30(5), 571-584. https://doi.org/10.1016/j.appdev. 2009.06.003.

Raffaelli, M., Crockett, L. J., \& Shen, Y. L. (2005). Developmental stability and change in self-regulation from childhood to adolescence. The Journal of Genetic Psychology, 166(1), 54-76. https://doi.org/10.3200/GNTP.166.1.54-76.

Rubin, D. B. (1976). Inference and missing data. Biometrika, 63(3), 581-592.

Sachdeva, S., Iliev, R., \& Medin, D. L. (2009). Sinning saints and saintly sinners: The paradox of moral self-regulation. Psychological Science, 20(4), 523-528. https:// doi.org/10.1111/j.1467-9280.2009.02326.x.

Schmid, K. L., Phelps, E., \& Lerner, R. M. (2011). Constructing positive futures: Modeling the relationship between adolescents' hopeful future expectations and intentional self regulation in predicting positive youth development. Journal of Adolescence, 34(6), 1127-1135. https://doi.org/10.1016/j.adolescence.2011.07. 009.

Shariff, A. F., \& Norenzayan, A. (2007). God is watching you: Priming God concepts increases prosocial behavior in an anonymous economic game. Psychological Science, 18(9), 803-809. https://doi.org/10.1111/j.1467-9280.2007.01983.x.

Sisk, C. L., \& Foster, D. L. (2004). The neural basis of puberty and adolescence. Nature Neuroscience, 7(10), 1040-1047.

Spear, L. P. (2000a). The adolescent brain and age-related behavioral manifestations. Neuroscience \& Biobehavioral Reviews, 24(4), 417-463. https://doi.org/10.1016/ S0149-7634(00)00014-2.

Spear, L. P. (2000b). Neurobehavioral changes in adolescence. Current Directions in Psychological Science, 9(4), 111-114. https://doi.org/10.1111/1467-8721.00072.

Steinberg, L. (2005). Cognitive and affective development in adolescence. Trends in Cognitive Sciences, 9(2), 69-74. https://doi.org/10.1016/j.tics.2004.12.005.

Steinberg, L. (2010). Commentary: A behavioral scientist looks at the science of adolescent brain development. Brain and Cognition, 72(1), 160-164. https://doi.org/ 10.1016/j.bandc.2009.11.003.

Vieno, A., Santinello, M., Pastore, M., \& Perkins, D. D. (2007). Social support, sense of community in school, and self-efficacy as resources during early adolescence: An integrative model. American Journal of Community Psychology, 39(1-2), 177-190. https://doi.org/10.1007/s10464-007-9095-2.

Wehmeyer, M. L., \& Shogren, K. A. (2017). The development of self-determination during adolescence. In M. Wehmeyer, K. Shogran, T. Little, \& S. Lopez (Eds.). Development of self-determination through the life-course (pp. 89-98). Dordrecht, Netherlands: Springer. https://doi.org/10.1007/978-94-024-1042-6_7.

Wentzel, K. R. (1993). Does being good make the grade? Social behavior and academic competence in middle school. Journal of Educational Psychology, 85(2), $357-364$.

Widaman, K. F., Ferrer, E., \& Conger, R. D. (2010). Factorial invariance within longitudinal structural equation models: Measuring the same construct across time. Child Development Perspectives, 4(1), 10-18. https://doi.org/10.1111/j.1750-8606.2009.00110.x.

Winterich, K. P., Aquino, K., Mittal, V., \& Swartz, R. (2013). When moral identity symbolization motivates prosocial behavior: The role of recognition and moral identity internalization. Journal of Applied Psychology, 98(5), 759-770. https://doi.org/10.1037/a0033177. 